\title{
Gonorrhea infection in women: prevalence, effects, screening, and management
}

This article was published in the following Dove Press journal:

International Journal of Women's Health

18 July 2011

Number of times this article has been viewed

\author{
Cheryl K Walker \\ Richard L Sweet \\ Women's Center for Health, \\ Department of Obstetrics and \\ Gynecology, University of California, \\ Davis School of Medicine, \\ Sacramento, CA, USA
}

\begin{abstract}
Gonorrhea is a set of clinical conditions resulting from infection with the sexuallyacquired bacterial pathogen Neisseria gonorrhoeae. Acquisition may involve multiple mucosal sites in the lower female genital tract, including the urethra, cervix, Bartholin's and Skene's glands, as well as the anorectal canal, pharynx, and conjunctivae. It may spread to the upper genital tract, uterine tubes, abdominal cavity, and other systemic sites. Gonorrhea is the second most commonly reported sexually-transmitted infection in the US and rates are higher among women than men. Women and infants are affected disproportionately by gonorrhea, because early infection may be asymptomatic and also because extension of infection is often associated with serious sequelae. Screening is critical for infection identification and the prevention or limitation of upper genital tract spread, and horizontal and vertical transmission. Routine genital screening is recommended annually for all sexually active women at risk for infection, including women aged $<25$ years and older women with one or more of the following risks: a previous gonorrhea infection, the presence of other sexually transmitted diseases, new or multiple sex partners, inconsistent condom use, commercial sex work, drug use, or human immunodeficiency virus infection with sexual activity or pregnancy. Pharyngeal gonococcal infections are common in adolescents, and direct culture screening is necessary to identify affected individuals. Nucleic acid amplification tests (NAATs) are considered the standard for screening and diagnosis. Although urine NAAT testing is most commonly used, there is growing support for vaginal swabs collected by providers or patients themselves. Resistance to all antibiotics currently recommended for the treatment of gonorrhea has been documented and complicates therapeutic strategies. The Centers for Disease Control and Prevention recommend treatment of gonorrhea with a single class of drugs, ie, the cephalosporins.
\end{abstract}

Keywords: gonorrhea, women, infection, treatment, cephalosporins

\section{Introduction}

Gonorrhea refers to a set of clinical conditions involving infection with the sexually acquired bacterial pathogen, Neisseria gonorrhoeae, identified microbiologically by its Gram-negative intracellular diplococci. N. gonorrhoeae may be acquired at multiple mucosal sites in the lower genital tract, including the urethra, cervix, Bartholin's and Skene's glands, as well as through the anorectal canal, pharynx, and conjunctivae. It may spread to the upper genital tract, uterine tubes, and abdominal cavity, as well as other systemic sites. With references to this condition dating back over 2000 years, gonorrhea is an old disease, with humans serving as the sole natural host.
Correspondence: Cheryl K Walker Women's Center for Health, Department of Obstetrics and Gynecology, University of California, Davis School of Medicine, 4869 Y Street, Suite 2500, Sacramento, CA 95817, USA

Tel +I 9167346670

Fax +I 9167346666

Email ckwalker@ucdavis.edu 


\section{Epidemiologic features}

\section{Prevalence}

Gonorrhea is a common infection, with recent Centers for Disease Control and Prevention (CDC) figures estimating more than 700,000 new cases in the US each year, only half of which are reported. ${ }^{1}$ In 2009, there were 301,174 cases of gonorrhea reported in the US, a rate of 99.1 cases per 100,000 people, a $10.5 \%$ decrease from the previous year. Gonorrhea follows chlamydial infections as the second most commonly reported sexually transmitted infection (STI) in the US. ${ }^{1}$ As a treatable STI, gonorrhea rates respond to public health interventions aimed at aggressive case finding and treatment, and between 1975 and 1997, rates fell 74\% in response to a national gonorrhea control program. Following the conclusion of that program, gonorrhea rates have remained relatively stable.

Overall rates and comparisons between subpopulations must be understood within the context that reported case results are greatly influenced by changes in public awareness, health care access, screening practices, resistance patterns, reporting practices, outbreaks of other STIs, and budgetary limitations that hamper the abilities of public health officials to monitor disease patterns accurately. ${ }^{1,2}$ In particular, rates of asymptomatic infections are subject to dramatic shifts based on alterations in screening behaviors. ${ }^{3-6}$

Reported rates of gonorrhea and other STIs are commonly held to represent the tip of the iceberg of true infection prevalence, in large part because roughly half of all gonococcal infections in women are asymptomatic. ${ }^{7}$ Some have cautioned that actual prevalence is likely to be roughly twice the reported rate. ${ }^{8}$ Problems that evolve from that paradigm are that many infected individuals harbor untreated infection for protracted periods of time, greatly increasing the potential both for transmission of infection to sex partners and development of complications due to more profound extension of the infection. ${ }^{1}$

Given the biased and incomplete nature of passive case reporting, active surveillance efforts are used to assess disease burden in selected higher risk populations. In 2009, the median state-specific gonorrhea test positivity among women aged 15-24 years in a subset of states, the District of Columbia, Puerto Rico, and the Virgin Islands, was ascertained through screening efforts in various settings: family planning clinics $1.0 \%$ (range $0.0 \%-3.4 \%$ ); prenatal clinics $1.2 \%$ (range $0.0 \%-5.5 \%$ ); women entering the National Job Training Program 1.6\% (0.0\%-5\%); and women entering juvenile corrections facilities $2.9 \%(0.0 \%-13.4 \%) .{ }^{1}$

\section{Geographic distribution}

Prevalence in the US varies by geography and demographics, with the highest risk profile in adolescent black women residing in urban locales in the South. The South has traditionally had the highest rates in the US, followed closely by the Midwest. State-reported gonorrhea rates fell in $84 \%$ of states between 2008 and 2009. In 2009, gonorrhea rates per 100,000 population by state ranged from 7.2 in Utah to 246.4 in Mississippi. The majority of people with gonorrhea reside in urban locations, with $60 \%$ of gonorrhea cases reported by the 50 most populous metropolitan areas that report to the CDC in 2009.

\section{Gender}

Traditionally, men were more likely to have gonorrhea, but rates equilibrated by 1996 and have remained similar since then. ${ }^{1}$ In 2009, the gonorrhea rate among women was higher than the rate among men, and the most common reporting source for women was private physicians/health maintenance organizations (30.9\%), followed by STI clinics (16.7\%), family planning clinics $(9.1 \%)$, other health department clinics (8.1\%), and emergency rooms (5.8\%).

\section{Race and age}

Gonorrhea rates are highest among blacks, and in 2009 the rate in black women was 17 times greater than the rate among white women. ${ }^{1}$ Adolescents and young adults bear the greatest burden of infection. Among females in 2009, black women aged 15-19 years and 20-24 years had the highest rates of gonorrhea (2614 and 2549 per 100,000, respectively).

\section{Education}

Education has been inversely correlated to behavioral risk-taking associated with the acquisition of STIs in adolescents. ${ }^{9-13}$ A recent study of self-reported STIs, including gonorrhea, chlamydia, and trichomoniasis, among young adult women confirmed that education is associated with decreased engagement in sexual risk behaviors and lower rates of STI diagnosis, but that those associations varied across racial strata, with college-educated black women reporting higher rates of STI compared with white women who had not completed high school. ${ }^{8}$

\section{Clinical manifestations}

Women and infants are affected disproportionately by gonorrhea, because early infection may be asymptomatic or subclinical and also because extension of infection is often 
associated with serious sequelae. The simplest gonococcal infections in women involve mucosal surfaces of the endocervix, urethra, anus, or pharynx. Most such infections are either silent or generate only mild symptoms, including discharge and mild irritation, that may or may not be appreciated until the infection spreads to the upper genital tract. Pharyngeal infections are nearly always asymptomatic. When an etiologic organism is isolated in the presence of cervicitis, it is typically Chlamydia trachomatis or N. gonorrhoeae.

Because cervicitis might be a sign of upper genital tract infection, women who seek medical treatment for a new episode of cervicitis should be assessed for pelvic inflammatory disease. An estimated 10\%-20\% of women with gonorrrhea or chlamydia may develop pelvic inflammatory disease if their infection is not identified and they do not receive adequate treatment. ${ }^{14}$ Among women with pelvic inflammatory disease, uterine tubal scarring can cause involuntary infertility in $20 \%$ of women, ectopic pregnancy in $9 \%$, and chronic pelvic pain in $18 \% .{ }^{15}$ Some cases of pelvic inflammatory disease have a severe presentation with abdominal pain and fever, and may result in tubo-ovarian abscesses and systemic infection. As with uncomplicated gonococcal infection, many women with pelvic inflammatory disease are asymptomatic or have subtle signs and symptoms of ongoing damage to uterine tubes, resulting in treatment delays in approximately $85 \%$ of women with pelvic inflammatory disease and enhancing the chance for long-term sequelae. ${ }^{15,16}$

Gonorrhea can become disseminated, with bacteremia leading on occasion to chronic joint infections and sepsis. Disseminated gonorrhea frequently results in petechial or pustular acral skin lesions, asymmetrical arthralgia, tenosynovitis, or septic arthritis. The infection is complicated occasionally by perihepatitis and rarely by endocarditis or meningitis.

Finally, gonorrhea is highly transmissible, both to sexual contacts and at birth. Infections in the neonate include conjunctivitis, blindness, sepsis, and joint infections.

\section{Screening}

Because gonorrhea is often asymptomatic in women, screening is critical for the identification of infection and the prevention or limitation of upper genital tract spread, and horizontal and vertical transmission. Data from a randomized controlled trial of chlamydia screening in a managed care setting suggest that such screening programs can reduce the incidence of pelvic inflammatory disease by as much as $60 \%{ }^{17}$

Because the prevalence of gonorrhea varies widely among communities and populations, targeted rather than widespread screening is recommended by the US Preventive Services Task Force and the CDC. Routine genital screening for $N$. gonorrhoeae is recommended annually for all sexually active women at risk for infection, including women aged $<25$ years and older women with one or more of the following risks: a previous gonorrhea infection, the presence of other STIs, new or multiple sex partners, inconsistent condom use, commercial sex work, drug use, or human immunodeficiency virus infection with sexual activity. ${ }^{18}$ Pharyngeal gonococcal infections are common in some segments of the population, especially adolescents, and pharyngeal culture screening is responsible for identification of up to one-quarter of infected adolescent women who would likely be missed with traditional genital tract screening. ${ }^{19-23}$

All pregnant women at risk for gonorrhea or living in an area in which the prevalence of $N$. gonorrhoeae is high should be screened at the first prenatal visit for $N$. gonorrhoeae. ${ }^{18}$ Pregnant women who test positive should be retested within approximately 3-6 months, and those who remain at high risk for gonococcal infection, including adolescents, should be retested also during the third trimester. ${ }^{24}$

Specific testing for $N$. gonorrhoeae is recommended because of the subtle and nonspecific nature of presentation in most women as well as the availability of highly sensitive and specific testing modalities. Although there are three ways to diagnose gonorrhea, ie, traditional culture, nucleic acid hybridization, and nucleic acid amplification tests (NAATs), NAATs are considered the standard for screening and diagnostic purposes currently. Culture requires collection of actual cells from infected mucosal surfaces, and is the only methodology approved for detection of $N$. gonorrhoeae from both genital (endocervical, urethral) and nongenital (anorectal, pharyngeal, and conjunctival) mucosal surfaces. Cultures can provide antimicrobial susceptibility results, and should be the test of choice in cases of suspected or documented treatment failure. Nucleic acid hybridization tests detect gonococcal DNA and some brands also test for chlamydial DNA; they are recommended for use on specimens collected from genital tract surfaces, including genital tract, vagina, and urine. The principal types of NAATs, ie, transcription-mediated amplification, polymerase chain reactions, and strand displacement amplification, detect and copy gonococcal DNA to enhance detection. NAATs are approved by the US Food and Drug Administration for use with urine, urethral, and endocervical samples, and some are cleared for use on vaginal swabs, but none are approved for use in specimens from the 
rectum, oropharynx, or conjunctivae due to concerns that specificity could be compromised by cross-reaction with nongonococcal Neisseria species. NAATs have demonstrated improved sensitivity and specificity compared with culture for the detection of $N$. gonorrhoeae at rectal and oropharyngeal sites among men. ${ }^{21,22,25,26}$ Numerous public and private laboratories have established performance specifications for using NAAT with vaginal, rectal, and pharyngeal swab specimens, thereby allowing results to be used for clinical management. Under these circumstances, NAATs are preferred for rectal, oropharyngeal, and conjunctival specimens. Liquid-based cervical cytology specimens appear to hold promise for NAAT testing, although test sensitivity using these specimens might be lower than those resulting from the use of cervical swab specimens. ${ }^{27}$

Although the standard female genital screening tool at most public health clinics is urine NAAT testing, there is growing support for vaginal swabs collected by providers and patients in clinical and nonclinical settings. Vaginal swab specimens perform at least as well as with other approved specimens using NAATs, and women find this screening strategy highly acceptable. ${ }^{31,32}$ In a study of women using long-acting contraception who remain at risk of STI acquisition, those randomized to self-collected vaginal swabs were more likely to complete screening than the women in the traditional clinical screening group. ${ }^{33}$ Another study showed that women recruited by the Internet demonstrated higher positivity of chlamydia than those attending a family planning clinic, providing an important at-risk market for self-collected vaginal swabs. ${ }^{34}$ Finally, as a practical matter, swabs reduce biological waste associated with urine testing.

In symptomatic women, the finding of $>10$ white blood cells per high powered field in vaginal fluid in the absence of trichomoniasis, may reflect endocervical inflammation caused by $C$. trachomatis or $N$. gonorrhoeae, ${ }^{28,29}$ and should increase motivation for empiric treatment.

Due to high prevalence of gonorrhea in juvenile detention and jail facilities, the CDC recommends universal screening at intake of adolescent and adult women up to 35 years of age or on the basis of local institutional prevalence data. ${ }^{1}$

Routine testing of inmates has the potential to diagnose a large portion of STIs in the community. When the Cook County Jail in Chicago stopped offering routine chlamydia and gonorrhea testing to all male inmates, approximately $90 \%$ fewer detainees were diagnosed with either disease and citywide diagnosis in males and females decreased by $9.3 \%$ for chlamydia and $12.9 \%$ for gonorrhea. ${ }^{5}$ Failure to perform universal screening in high-risk populations represents a missed opportunity to uncover substantial numbers of infections. When New York City began routine testing for chlamydia and gonorrhea among incarcerated men less than 35 years of age, the citywide diagnosis of chlamydia and gonorrhea increased by $59 \%$ and $4 \%$, respectively. ${ }^{6}$ Kahn examined the link between incarceration and sexually transmitted infections from a social network perspective in Brooklyn, NY $(n=343)$ and found that acquisition of an STI was highly associated with a history of incarceration. ${ }^{30}$

Persons with gonorrhea should be tested for other STIs. Outside of the neonatal period, evidence of gonococcal infection at any site is considered virtually $100 \%$ indicative of sexual contact. ${ }^{35}$

\section{Management}

\section{Antimicrobial-resistant N. gonorrhoeae}

Gonorrhea treatment is complicated by the ability of $N$. gonorrhoeae to develop resistance to antimicrobial therapies. ${ }^{36}$ In 1986, the CDC developed a national surveillance program called the Gonococcal Isolate Surveillance Project to monitor gonococcal isolate resistance patterns in the US among selected STI clinics in approximately 25-30 Gonococcal Isolate Surveillance Project sentinel sites and 4-5 regional laboratories.

Penicillin was the original treatment choice for gonococcal infections until the discovery in 1976 of resistance mediated by plasmid production of $\beta$-lactamase. ${ }^{37}$ Rates of penicillinase-producing $N$. gonorrhoeae have risen steadily since then, and chromosomal-mediated resistant $N$. gonorrhoeae has emerged to tetracycline, cephosporins, spectinomycin, and aminoglycosides. ${ }^{38}$ Newer findings include plasmid-mediated tetracycline resistance resulting from acquisition of a tet-M gene $\mathrm{g}^{38-40}$ and fluoroquinolone resistance. ${ }^{1,41}$

Treatment with quinolones used to be the mainstay of $N$. gonorrhoeae treatment in the US, but resistant strains spread throughout the US and the world, ${ }^{42}$ leading to removal of that class of drugs from recommendations for the treatment of gonorrhea and pelvic inflammatory disease in April 2007.43 Provider compliance has been excellent, with the proportion of Gonococcal Isolate Surveillance Project patients treated with fluoroquinolones (ciprofloxacin, ofloxacin, or levofloxacin) at $0.5 \%$ and the proportion treated with cephalosporins at $96.2 \%$ in 2009 . By $2009,23.5 \%$ of isolates collected from Gonococcal Isolate Surveillance Project sites were resistant to penicillin, tetracycline, or ciprofloxacin. ${ }^{1}$ 
Decreased susceptibility has been documented to azithromycin in US isolates of $N$. gonorrhoeae, ${ }^{1}$ and resistant strains have been documented internationally. ${ }^{44} 47$ Most of the treatment failures resulting from use of oral cephalosporins have been reported from Asian and European countries, ${ }^{48-51}$ although one possible case was reported in Hawaii in 2001. ${ }^{52}$ To ensure appropriate antibiotic therapy, clinicians should ask patients testing positive for gonorrhea about recent travel to and sexual activity in these countries. Two cases of suspected treatment failure with ceftriaxone have been reported..$^{53}$ Decreased susceptibility of $N$. gonorrhoeae to cephalosporins and other antimicrobials is expected to continue to spread; therefore, state and local surveillance for antimicrobial resistance is crucial for guiding local therapy recommendations. ${ }^{36}$ The CDC website (http://www.cdc.gov/std/gisp) and state health departments can provide the most current information.

\section{Antimicrobial regimens}

While gonorrhea is a bacterial infection that responds to a number of antibiotics, resistance to all antibiotic treatments currently recommended for the treatment of gonorrhea has been documented and complicate therapeutic strategies. The CDC released new STI treatment guidelines in 2010, with evidence-based antibiotic regimens designed to treat gonorrhea by anatomic site of infection (Table 1). ${ }^{35}$ The recommended treatment of gonorrhea has been limited to a single class of drugs, the cephalosporins. The regimens listed in Table 1 are recommended for treatment of uncomplicated lower genital tract and anorectal gonococcal infection in women. Treatment should be administered or dispensed at the time of diagnosis to maximize patient adherence. Patients should be instructed to abstain from sexual intercourse until therapy is completed and until they and their sex partners no longer have symptoms.

\section{Uncomplicated gonococcal infections}

Ceftriaxone has been shown to cure $99.2 \%$ of uncomplicated urogenital and anorectal and $98.9 \%$ of pharyngeal infections in published clinical trials. ${ }^{49,50}$ While a dose of $125 \mathrm{mg}$ was recommended until recently for lower genital and anorectal infection, a doubling of the dose is recommended to reduce development of resistance and to cover unrecognized oropharyngeal infection. Other injectable cephalosporins recommended for gonococcal treatment include ceftizoxime, cefoxitin, and cefotaxime. None of these offers any advantage over ceftriaxone for urogenital infection, and efficacy for pharyngeal infection is less certain. ${ }^{54,55}$ The only recommended oral choice for gonorrhea is cefixime, which has a lower cure rate at $97.5 \%$ for uncomplicated urogenital and anorectal and $92.3 \%$ of pharyngeal gonococcal infections. Published sources estimate that approximately 50 patients are thought to have failed oral cephalosporin treatment. ${ }^{49,56-59}$

The $2 \mathrm{~g}$ dose of azithromycin should be used only in limited circumstances because of concerns about resistance development to macrolides. The $1 \mathrm{~g}$ dose is not recommended because of documented treatment failures, and concerns about rapid emergence of antimicrobial resistance are even greater than with the $2 \mathrm{~g}$ dose. ${ }^{45,59,60}$

All alternative regimens for gonorrhea are considered inferior to ceftriaxone, because of lower efficacy in urogenital and rectal infection and unacceptably low cure rates for oropharyngeal infection. Cure of gonococcal infection may become increasingly elusive, given growing clinical and in vitro resistance patterns. ${ }^{61}$

Gonococcal infections of the pharynx are more difficult to eradicate than infections at urogenital and anorectal sites, leaving ceftriaxione $250 \mathrm{mg}$ intramuscularly as the single drug of choice. ${ }^{62}$ Two treatment failures have been reported and sensitivity of gonococcal isolates to ceftriaxone has been steadily declining..$^{53,61}$ This trend is expected to continue.

Women diagnosed with gonococcal conjunctivitis should undergo saline lavage of the infected eye and be treated with high-dose ceftriaxone. ${ }^{63}$

\section{Complicated gonococcal infections}

Disseminated gonococcal infection is a serious infection, for which hospitalization is recommended in consultation with an infectious disease specialist, both for initiation of treatment as well as for completion of a diagnostic evaluation for endocarditis and meningitis. Parenteral therapy should be continued for 24-48 hours after improvement begins, at which time therapy can be switched to oral therapy to complete at least 1 week of antimicrobial therapy (Table 1). Prolonged duration of therapy is required for other complicated infections as well, including 10-14 days for meningitis, and at least 4 weeks for endocarditis (Table 1).

\section{Pelvic inflammatory disease}

Given the asymptomatic nature of lower genital tract gonococcal infection, nearly one in five women who do not 
Table I Treatment recommendations for gonococcal infections in women'

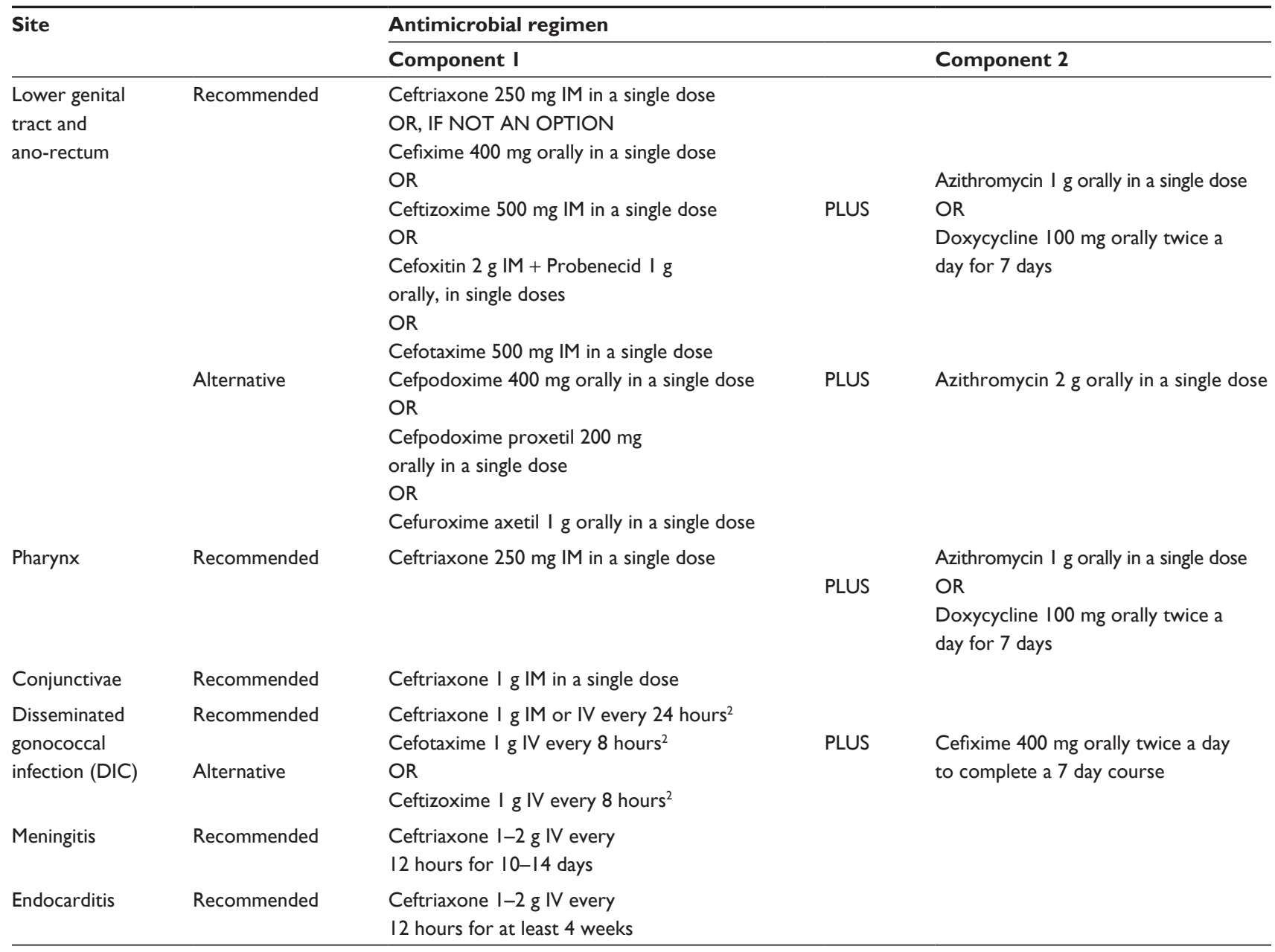

Notes: 'Adapted from the 2010 CDC STD treatment guidelines; 35 2Parenteral treatment should be continued until 24 hours following the improvement of clinical symptoms.

receive treatment will develop pelvic inflammatory disease. ${ }^{64}$ Women diagnosed with pelvic inflammatory disease may have lower and or upper genital tract evidence of a number of microbes, including $N$. gonorrhoeae and C. trachomatis, and a large number of Gram-negative and anaerobic bacteria. Negative lower tract screening for certain bacteria does not rule out upper reproductive tract infection, and treatment recommendations favor coverage against these various organisms (Table 2). Treatment may be administered in inpatient or outpatient settings, and there are regimens that are primarily parenteral and others that are primarily oral, choices which should be undertaken based on the severity of the infection. ${ }^{35}$

\section{Cotreatment for $C$. trachomatis}

Because women with gonorrhea are frequently coinfected with chlamydia, treatment for gonococcal infection at all sites and of all levels of severity should include antibiotics that eradicate both $N$. gonorrhoeae and C. trachomatis. ${ }^{65}$ Because most gonococci in the US are susceptible to doxycycline and azithromycin, routine cotreatment might also hinder the development of antimicrobial-resistant $N$. gonorrhoeae. Limited data suggest that dual treatment with azithromycin might enhance treatment efficacy for pharyngeal infection when using oral cephalosporins. ${ }^{66}$

\section{Special populations}

Pregnant women and women who are HIV-infected and diagnosed with gonorrhea should be treated according to standard recommendations.

\section{Allergic reactions}

Up to $10 \%$ of individuals with a history of penicillin allergy develop an adverse reaction to first-generation cephalosporins, and fewer react to third-generation cephalosporins. ${ }^{67}$ Cephalosporin use should be avoided only 
Table 2 Treatment recommendations for pelvic inflammatory disease'

\begin{tabular}{|c|c|c|c|c|}
\hline \multirow{2}{*}{$\begin{array}{l}\text { Route of } \\
\text { administration }\end{array}$} & & \multicolumn{3}{|l|}{ Antimicrobial regimen } \\
\hline & & Parenteral component $^{2}$ & & Oral component \\
\hline \multirow[t]{12}{*}{ Parenteral + oral } & Regimen A & Cefotetan 2 g IV every 12 hours & & Doxycycline $100 \mathrm{mg}$ orally twice a \\
\hline & & OR & PLUS & day \\
\hline & & Cefoxitin 2 g IV every 6 hours & & to complete a I4-day course \\
\hline & & PLUS & & PLUS, when tubo-ovarian abscess is \\
\hline & & Doxycycline $100 \mathrm{mg}$ orally or & & present, \\
\hline & & IV every 12 hours & & \\
\hline & Regimen B & $\begin{array}{l}\text { Clindamycin } 900 \text { mg IV every } 8 \text { hours } \\
\text { PLUS }\end{array}$ & PLUS & $\begin{array}{l}\text { Clindamycin } 450 \mathrm{mg} \text { orally four times } \\
\text { a day to complete a | } 4 \text {-day course }\end{array}$ \\
\hline & & $\begin{array}{l}\text { Gentamicin loading dose } 2 \mathrm{mg} / \mathrm{kg} \mathrm{IV} \text { or IM, } \\
\text { followed by a maintenance dose of } \mathrm{I} .5 \mathrm{mg} / \mathrm{kg} \\
\text { every } 8 \text { hours. Single daily dosing }(3-5 \mathrm{mg} / \mathrm{kg}) \\
\text { can be substituted }\end{array}$ & & OR \\
\hline & Alternative & Ampicillin/Sulbactam $3 \mathrm{~g}$ IV every 6 hours & & \\
\hline & & PLUS & PLUS & Metronidazole 500 mg orally \\
\hline & & Doxycycline $100 \mathrm{mg}$ orally or IV every & & two times a day tocomplete a \\
\hline & & 12 hours & & 14-day course \\
\hline \multirow[t]{22}{*}{ Oral } & Recommended & & & $\begin{array}{l}\text { Ceftriaxone } 250 \mathrm{mg} \text { IM in a } \\
\text { single dose }\end{array}$ \\
\hline & & & & OR \\
\hline & & & & Cefoxitin $2 \mathrm{~g}$ IM in a single dose \\
\hline & & & & administered concurrently in a \\
\hline & & & & single dose \\
\hline & & & & OR \\
\hline & & & & $\begin{array}{l}\text { Other parenteral third-generation } \\
\text { cephalosporin }\end{array}$ \\
\hline & & & & (eg, ceftizoxime or cefotaxime) \\
\hline & & & & PLUS \\
\hline & & & & Doxycycline $100 \mathrm{mg}$ orally twice \\
\hline & & & & a day for 14 days \\
\hline & & & & WITH or WITHOUT \\
\hline & & & & Metronidazole $500 \mathrm{mg}$ orally twice \\
\hline & & & & a day for 14 days \\
\hline & Alternative & & & Ceftriaxone $250 \mathrm{mg}$ IM in a \\
\hline & & & & single dose \\
\hline & & & & PLUS \\
\hline & & & & Azithromycin I g orally once \\
\hline & & & & a week for two weeks \\
\hline & & & & WITH or WITHOUT \\
\hline & & & & Metronidazole $500 \mathrm{mg}$ orally \\
\hline & & & & twice a day for 14 days \\
\hline
\end{tabular}

Notes: 'Adapted from the 2010 CDC STD treatment guidelines; ${ }^{35}{ }^{2}$ Parenteral treatment should be continued until 24 hours following the improvement of clinical symptoms.

in those with a history of a severe reaction to penicillin (eg, anaphylaxis, Stevens Johnson syndrome, and toxic epidermal necrolysis), ${ }^{68}$ and further treatment decisions should be made in consultation with an infectious disease specialist.

\section{Follow-up}

Women treated with any of the recommended or alternative regimens for an uncomplicated episode of $N$. gonorrhoeae do not need a test-of-cure 3-4 weeks after completing therapy, but should be retested 3 months after treatment or the next time they seek medical care irrespective of partner treatment. ${ }^{69}$ Because reinfection within a few months is common, ${ }^{70-72}$ patient education regarding safer sexual practices and partner referral is warranted. If symptoms persist following treatment, women should be tested for other pathogens and re-evaluated by culture for N. gonorrhoeae; any gonococci isolated should be tested for antimicrobial susceptibility.

Sex partners of patients with $N$. gonorrhoeae infection whose last sexual contact with the patient was within 
60 days of the onset of symptoms or diagnosis of infection in the patient should be evaluated and treated for $N$. gonorrhoeae and $C$. trachomatis. If a patient's last sexual intercourse was $>60$ days before onset of symptoms or diagnosis, the patient's most recent sex partner should be treated. For those whose partners' treatment cannot be ensured or is unlikely, delivery of antibiotic therapy for gonorrhea (as well as for chlamydia) by the patients to their partners should be considered, accompanied by efforts to educate partners about symptoms and to encourage partners to seek clinical evaluation. ${ }^{73,74}$

Suspected treatment failure is less common than reinfection, but has been reported, especially among persons receiving regimens other than the $250 \mathrm{mg}$ dose of ceftriaxone. ${ }^{49,53,56-58}$ Clinicians of patients with suspected treatment failure or persons found to harbor a resistant strain should consult an infectious disease specialist, conduct culture and susceptibility testing of relevant clinical specimens, re-treat with at least $250 \mathrm{mg}$ of ceftriaxone intramuscularly or intravenously, ensure partner treatment, and report the situation to the CDC through state and local public health authorities. ${ }^{35}$

\section{Disclosure}

The authors report no conflicts of interest in this work.

\section{References}

1. Centers for Disease Control and Prevention. Sexually Transmitted Disease Surveillance 2009. Atlanta: US Department of Health and Human Services; 2010. Available from: http://www.cdc.gov/std/stats09/ surv2009-Complete.pdf. Accessed June 17, 2011.

2. Centers for Disease Control and Prevention. Gonorrhea - United States, 1998. MMWR Morb Mortal Wkly Rep. 2000;49:538-542.

3. Majdzadeh R, Pourmalek F. A conditional probability approach to surveillance system sensitivity assessment. Public Health. 2008;122: $53-60$.

4. Bernstein KT, Marcus JL, Nieri G, Philip SS, Klausner JD. Rectal gonorrhea and chlamydia reinfection is associated with increased risk of HIV seroconversion. J Acquir Immune Defic Syndr. 2010;53:537-543.

5. Broad J, Cox T, Rodriguez S, et al. The impact of discontinuation of male STD screening services at a large urban county jail: Chicago, 2002-2004. Sex Transm Dis. 2009;36(Suppl 2):S49-S52.

6. Pathela P, Hennessy RR, Blank S, Parvez F, Franklin W, Schillinger JA. The contribution of a urine-based jail screening program to citywide male Chlamydia and gonorrhea case rates in New York City. Sex Transm Dis. 2009;36(Suppl 2):S58-S61.

7. Hook EW, III, Handsfield HH. Gonococcal infections in the adult. In: Holmes KK, Sparling PF, Stamm WE, et al, editors. Sexually Transmitted Diseases. 4th ed. New York: McGraw-Hill; 2008.

8. Annang L, Walsemann KM, Maitra D, Kerr JC. Does education matter? Examining racial differences in the association between education and STI diagnosis among black and white young adult females in the US. Public Health Rep. 2010;125(Suppl 4):110-121.

9. Halpern CT, Joyner K, Udry JR, Suchindran C. Smart teens don't have sex (or kiss much either). J Adolesc Health. 2000;26:213-225.
10. Zweig JM, Phillips SD, Lindberg LD. Predicting adolescent profiles of risk: looking beyond demographics. $J$ Adolesc Health. 2002;31: 343-353.

11. Ford CA, Pence BW, Miller WC, et al. Predicting adolescents' longitudinal risk for sexually transmitted infection: results from the National Longitudinal Study of Adolescent Health. Arch Pediatr Adolesc Med. 2005;159:657-664.

12. Ohannessian CM, Crockett LJ. A longitudinal investigation of the relationship between educational investment and adolescent sexual activity. J Adolesc Res. 1993;8:167-182.

13. Scott-Jones D, White AB. Correlates of sexual activity in early adolescence. $J$ Early Adolesc. 1990;10:221-238.

14. Haggarty CL, Gottlieb S, Taylor BD, Low N, Xu F, Ness RB. Risk of sequelae after Chlamydia trachomatis genital infection in women. J Infect Dis. 2010;201(Suppl 2):S134-S155.

15. Westrom L, Joesoef R, Reynolds G, Hagdu A, Thompson SE. Pelvic inflammatory disease and fertility: a cohort study of 1,844 women with laparoscopically verified disease and 657 control women with normal laparoscopy. Sex Transm Dis. 1992;9:185-192.

16. Hillis SD, Joesoef R, Marchbanks PA, Wasserheit JN, Cates W Jr, Westrom L. Delayed care of pelvic inflammatory disease as a risk factor for impaired fertility. Am J Obstet Gynecol. 1993;168: 1503-1509.

17. Scholes D, Stergachis A, Heidrich FE, Andrilla H, Holmes KK, Stamm WE. Prevention of pelvic inflammatory disease by screening for cervical chlamydial infection. $N$ Engl J Med. 1996;34:1362-1366.

18. US Preventive Services Task Force. Screening for gonorrhea: recommendation statement. Ann Fam Med. 2005;3:263-267.

19. Giannini CM, Kim HK, Mortensen J, Mortensen J, Marsolo K, Huppert J. Culture of non-genital sites increases the detection of gonorrhea in women. J Pediatr Adolesc Gynecol. 2010;23:246-252.

20. Mayer KH, Klausner JD, Handsfield HH. Intersecting epidemics and educable moments: sexually transmitted disease risk assessment and screening in men who have sex with men. Sex Transm Dis. 2001;28: 464-467.

21. Schachter J, Moncada J, Liska S, et al. Nucleic acid amplification tests in the diagnosis of chlamydial and gonococcal infections of the oropharynx and rectum in men who have sex with men. Sex Transm Dis. 2008;35:637-642.

22. Mimiaga MJ, Mayer KH, Reisner SL, et al. Asymptomatic gonorrhea and chlamydial infections detected by nucleic acid amplification tests among Boston area men who have sex with men. Sex Transm Dis. 2008; 35:495-498.

23. Linhart Y, Shohat T, Amitai Z, et al. Sexually transmitted infections among brothel-based sex workers in Tel-Aviv area, Israel: high prevalence of pharyngeal gonorrhoea. Int J STD AIDS. 2008;19: 656-659.

24. Aggarwal A, Spitzer RF, Caccia N, Stephens D, Johnstone J, Allen L. Repeat screening for sexually transmitted infection in adolescent obstetric patients. J Obstet Gynaecol Can. 2010;32:956-961.

25. Bachmann LH, Johnson RE, Cheng H, et al. Nucleic acid amplification tests for diagnosis of Neisseria gonorrhoeae oropharyngeal infections. J Clin Microbiol. 2009;47:902-907.

26. Bachmann LH, Johnson RE, Cheng H, et al. Nucleic acid amplification tests for diagnosis of Neisseria gonorrhoeae and Chlamydia trachomatis rectal infections. J Clin Microbiol. 2010;48:1827-1832.

27. Chernesky M, Freund GG, Hook E III, et al. Detection of Chlamydia trachomatis and Neisseria gonorrhoeae infections in North American women by testing SurePath liquid-based Pap specimens in APTIMA assays. J Clin Microbiol. 2007;45:2434-2438.

28. Steinhandler L, Peipert JF, Heber W, et al. Combination of bacterial vaginosis and leukorrhea as a predictor of cervical chlamydial or gonococcal infection. Obstet Gynecol. 2002;99:603-607.

29. Geisler WM, Yu S, Venglarik M, et al. Vaginal leucocyte counts in women with bacterial vaginosis: relation to vaginal and cervical infections. Sex Transm Infect. 2004;80:401-405. 
30. Khan MR, Epperson MW, Mateu-Gelabert P, Bolyard M, Sandoval M, Friedman SR. Incarceration, sex with an STI- or HIV-infected partner, and infection with an STI or HIV in Bushwick, Brooklyn, NY: a social network perspective. Am J Public Health. 2011;101: $1110-1117$.

31. Schachter J, Chernesky MA, Willis DE, et al. Vaginal swabs are the specimens of choice when screening for Chlamydia trachomatis and Neisseria gonorrhoeae: results from a multicenter evaluation of the APTIMA assays for both infections. Sex Transm Dis. 2005;32:725-728

32. Doshi JS, Power J, Allen E. Acceptability of chlamydia screening using self-taken vaginal swabs. Int J STD AIDS. 2008;19: 507-509.

33. Graseck AS, Secura GM, Allsworth JE, Madden T, Peipert JF. Home compared with clinic-based screening for sexually transmitted infections: a randomized controlled trial. Obstet Gynecol. 2010;116: 1311-1318.

34. Gaydos CA, Barnes M, Aumakhan B, et al. Chlamydia trachomatis agespecific prevalence in women who used an internet-based self-screening program compared to women who were screened in family planning clinics. Sex Transm Dis. 2011;38:74-78.

35. Centers for Disease Control and Prevention. Sexually transmitted disease treatment guidelines. 2010. Available from: http://www.cdc. gov/std/treatment/2010/STD-Treatment-2010-RR5912.pdf. Accessed June 17, 2010.

36. Workowski KA, Berman SM, Douglas JM Jr. Emerging antimicrobial resistance in Neisseria gonorrhoeae: urgent need to strengthen prevention strategies. Ann Intern Med. 2008;148:606-613.

37. Phillips I. Beta-lactamase producing penicillinase-resistant gonococcus Lancet. 1976;2:656.

38. Centers for Disease Control and Prevention. Sentinel surveillance system for antimicrobial resistance in clinical isolates of Neisseria gonorrhea. MMWR Morb Mortal Wkly Rep. 1987;36:585.

39. Centers for Disease Control and Prevention. Tetracycline-resistant Neisseria gonorrhea - Georgia, Pennsylvania, New Hampshire. MMWR Morb Mortal Wkly Rep. 1985;34:563.

40. Morse SA. High-level tetracycline resistance is the result of acquisition of streptococcal tet-M determinant. Antimicrob Agents Chemother. 1986;30:664.

41. Fox KK, Knapp JS, Holmes KK, et al. Antimicrobial resistance in Neisseria gonorrhoeae in the United States, 1988-1994: the emergence of decreased susceptibility to the fluoroquinolones. $J$ Infect Dis. 1997;175:1396-1403.

42. Tapsall JW. What management is there for gonorrhea in the postquinolone era? Sex Transm Dis. 2006;33:8-10.

43. Centers for Disease Control and Prevention. Update to CDC's sexually transmitted diseases treatment guidelines, 2006: fluoroquinolones no longer recommended for treatment of gonococcal infections. $M M W R$ Morb Mortal Wkly Rep. 2007;56:332-336.

44. Palmer HM, Young H, Winter A, et al. Emergence and spread of azithromycin-resistant Neisseria gonorrhoeae in Scotland. J Antimicrob Chemother. 2008;62:490.

45. Chisholm SA, Neal TJ, Alawattegama AB, et al. Emergence of highlevel azithromycin resistance in Neisseria gonorrhoeae in England and Wales. J Antimicrob Chemother. 2009;64:353.

46. Starnino S, Stefanelli P; Neisseria gonorrhoeae Italian Study Group: azithromycin-resistant Neisseria gonorrhoeae strains recently isolated in Italy. J Antimicrob Chemother. 2009;63:1200.

47. Deguchi T, Nakane K, Yasuda M, Maeda S. Emergence and spread of drug resistant Neisseria gonorrhoeae. J Urol. 2010;184:851-858.

48. Takahata S, Senju N, Osaki Y, Yoshida T, Ida T. Amino acid substitutions in mosaic penicillin-binding protein 2 associated with reduced susceptibility to cefixime in clinical isolates of Neisseria gonorrhoeae. Antimicrob Agents Chemother. 2006;50:3638-3645.

49. Yokoi S, Deguchi T, Ozawa T, et al. Threat to cefixime treatment for gonorrhea. Emerg Infect Dis. 2007;13:1275-1277.
50. Pandori M, Barry PM, Wu A, et al. Mosaic penicillin-binding protein 2 in Neisseria gonorrhoeae isolates collected in 2008 in San Francisco, California. Antimicrob Agents Chemother. 2009;53:4032-4034.

51. Unemo M, Golparian D, Syversen G, Vestrheim DF, Moi H. Two cases of verified clinical failures using internationally recommended first-line cefixime for gonorrhoea treatment, Norway, 2010. Euro Surveill. 2010; 15:19721.

52. Wang SA, Lee MVC, O'Connor N, et al. Multidrug-resistant Neisseria gonorrhoeae with decreased susceptibility to cefixime - Hawaii, 2001. Clin Infect Dis. 2003;37:849-852.

53. Tapsall J, Read P, Carmody C, et al. Two cases of failed ceftriaxone treatment in pharyngeal gonorrhoea verified by molecular microbiological methods. J Med Microbiol. 2009;58(5):683-687.

54. Moran JS, Levine WC. Drugs of choice for the treatment of uncomplicated gonococcal infections. Clin Infect Dis. 1995;20(Suppl 1):S47-S65.

55. Newman LM, Moran JS, Workowski KA. Update on the management of gonorrhea in adults in the United States. Clin Infect Dis. 2007;44(Suppl3): S84-S101.

56. Lo JY, Ho KM, Leung AO, et al. Ceftibuten resistance and treatment failure of Neisseria gonorrhoeae infection. Antimicrob Agents Chemother. 2008;52:3564-3567.

57. Deguchi T, Yasuda M, Yokoi S, et al. Treatment of uncomplicated gonococcal urethritis by double-dosing of $200 \mathrm{mg}$ cefixime at a $6-\mathrm{h}$ interval. J Infect Chemother. 2003;9:35-39.

58. Muratani T, Akasaka S, Kobayashi T, et al. Outbreak of cefozopran (penicillin, oral cephems, and aztreonam)-resistant Neisseria gonorrhoeae in Japan. Antimicrob Agents Chemother. 2001;45:3603-3606.

59. Waters LJ, Boag FC, Betournay R. Efficacy of azithromycin $1 \mathrm{~g}$ single dose in the management of uncomplicated gonorrhoea. Int J STD AIDS. 2005; $16: 84$

60. McLean CA, Wang SA, Hoff GL, et al. The emergence of Neisseria gonorrhoeae with decreased susceptibility to azithromycin in Kansas City, Missouri, 1999 to 2000. Sex Transm Dis. 2004;31:73-78.

61. Unemo M, Golparian D, Hestner A. Ceftriaxone treatment failure of pharyngeal gonorrhoea verified by international recommendations, Sweden, July 2010. Euro Surveill. 2011;16:19792.

62. Ota KV, Fisman DN, Tamari IE, et al. Incidence and treatment outcomes of pharyngeal Neisseria gonorrhoeae and Chlamydia trachomatis infections in men who have sex with men: a 13-year retrospective cohort study. Clin Infect Dis. 2009;48:1237-1243.

63. Haimovici R, Roussel TJ. Treatment of gonococcal conjunctivitis with single-dose intramuscular ceftriaxone. Am J Ophthalmol. 1989;107: 511-514.

64. Haggerty CL, Ness RB, Amortegui A, et al. Endometritis does not predict reproductive morbidity after pelvic inflammatory disease. Am J Obstet Gynecol. 2003;188:141-148.

65. Lyss SB, Kamb ML, Peterman TA, et al. Chlamydia trachomatis among patients infected with and treated for Neisseria gonorrhoeae in sexually transmitted disease clinics in the United States. Ann Intern Med. 2003; 139:178-185

66. Sathia L, Ellis B, Phillip S, et al. Pharyngeal gonorrhoea - is dual therapy the way forward? Int J STD AIDS. 2007;18:647-648.

67. Yates AB. Management of patients with a history of allergy to betalactam antibiotics. Am J Med. 2008;121:572-576.

68. Pichichero ME. A review of evidence supporting the American Academy of Pediatrics recommendation for prescribing cephalosporin antibiotics for penicillin-allergic patients. Pediatrics. 2005;115:1048-1057.

69. Hosenfeld CB, Workowski KA, Berman S, et al. Repeat infection with chlamydia and gonorrhea among females: a systematic review of the literature. Sex Transm Dis. 2009;36:478-489.

70. Peterman TA, Tian LH, Metcalf CA, et al. High incidence of new sexually transmitted infections in the year following a sexually transmitted infection: a case for rescreening. Ann Intern Med. 2006;145:564-572.

71. Fung M, Scott KC, Kent CK, et al. Chlamydial and gonococcal reinfection among men: a systematic review of data to evaluate the need for retesting. Sex Transm Infect. 2007;83:304-309. 
72. Kissinger PJ, Reilly K, Taylor SN, et al. Early repeat Chlamydia trachomatis and Neisseria gonorrhoeae infections among heterosexual men. Sex Transm Dis. 2009;36:498-500.

73. Golden MR, Whittington WL, Handsfield HH, et al. Effect of expedited treatment of sex partners on recurrent or persistent gonorrhea or chlamydial infection. N Engl J Med. 2005;352:676-685.
74. Kissinger P, Mohammed H, Richardson-Alston G, et al. Patientdelivered partner treatment for male urethritis: a randomized, controlled trial. Clin Infect Dis. 2005;41:623-629.

International Journal of Women's Health

Dovepress

\section{Publish your work in this journal}

The International Journal of Women's Health is an international, peerreviewed open-access journal publishing original research, reports, reviews and commentaries on all aspects of women's healthcare including gynecology, obstetrics, and breast cancer. Subject areas include: Chronic conditions (migraine headaches, arthritis, osteoporosis);

Endocrine and autoimmune syndromes; Sexual and reproductive health; Psychological and psychosocial conditions. The manuscript management system is completely online and includes a very quick and fair peer-review system. Visit http://www.dovepress.com/ testimonials.php to read real quotes from published authors. 